\title{
A ORIENTAÇÃO VALORATIVA NA MANUTENÇÃO DO PRECONCEITO FEMININO: CONSISTÊNCIA CORRELACIONAL ENTRE OS VALORES HUMANOS E SEXISMO AMBIVALENTE
}

\section{Values Of The Orientation As Maintenance Of The Feminine Preconception: Consistency Correlactional Between Ambivalent Sexism And Human Values}

Nilton S. Formiga ${ }^{1}$

\section{Resumo}

Muito se tem buscado explicar a respeito do problema do preconceito, principalmente, o feminino; os valores humanos têm revelado seguras explicações quanto à manifestação e manutenção deste fenômeno. Tal fato se deve porque o construto dos valores é capaz de orientar escolhas, atitudes, avaliação comportamental e situações sociais nas relações interpessoais. Com isso, é bem possível que exista uma base normativa que guie as atitudes e comportamentos preconceituosos frente às mulheres. No presente estudo, duas amostras, uma com 668 sujeitos e outra 795, com idade de 18 a 56 anos, de ambos os sexos, das cidades de Palmas e João Pessoa. Estes responderam o inventário de sexismo ambivalente, valores humanos e dados sociodemográficos. Os resultados se revelaram bem semelhante aos encontrados em estudos anteriores que relacionam sexismo e valores. Assim, o critério de orientação valorativa pessoal explicou o sexismo hostil e benévolo, e o social, apenas com o benévolo.

Palavras-chave: Preconceito; Valores humanos; Sexismo ambivalente.

1 Mestre em Psicologia Social pela Universidade Federal do Paraíba, onde atualmente leciona. Endereço: Av. Guarabira, 133, Bairro de Manaíra, CEP: 58038-140. João Pessoa - PB. E-mail: nsformiga@yahoo.com. 


\section{Abstract:}

Much has search to explain about the problem of the preconception; the human values have disclosed to safe explanations how much the manifestation and maintenance of this problem. Such fact if must for being this construct able guiding choices, attitudes, mannering evaluation and social situations. It is well possible that exists a normative base that guides the attitudes and behaviors against to women. Two samples had composed this study, having as respondent of the inventory of ambivalent sexism, human values and partnerdemographic data, citizens with age between 18 and 56 years of both the sexs, of the cities of Palmas and João Pessoa. The results if had disclosed well similar to the joined one in studies that relate preconception and values. The criterion of personal values of orientation explained the hostile sexism and benevolent, and the social one, only with benevolent.

Keywords: Prejudice; Human values; Ambivalent sexism.

\section{Introdução}

Apesar do avanço social e profissional que as mulheres vêm ocupando atualmente na sociedade, parece existir nos espaços intergrupais uma ligeira impressão de mudança quanto aos direitos e deveres exigidos por elas em termos de sua valorização e igualdade em relação ao seu cumprimento assumido pelos homens. Se refletirmos melhor, é possível que essa mudança venha compor um viés atribuicional em relação à discriminação feminina; esse problema não tem acabado coisa nenhuma, talvez sim apresentando alguma diminuição significativa na sua manifestação direta, a qual manifesta novos esquemas mentais na forma de discriminar, ganhando força na apresentação de atitudes preconceituosas numa versão sutil ou camuflada, passando despercebida quanto à saliência de um fenômeno concreto (Formiga, 2004; Pettigrew \& Meertens, 1995; Swim, Aikin, Hall \& Hunter, 1995, Torres, 1998, Tougas, Brown, Beaton \& Joly, 1995).

Tal fato vem salientar, segundo Monte e Formiga (2000), uma dicotomia entre o pensar e 0 fazer do sujeito em relação à concordância ou não da expressão aberta do preconceito, revelando, assim, uma manutenção discreta na qual alude a desejabilidade social do comportamento e atitude preconceituosa, o que leva a crer na sutileza desse fenômeno refletindo em termos da não existência do preconceito ou o seu contínuo desaparecimento, e mais, deflagra-se práticas discriminatórias 'politicamente corretas' em relação às mulheres (Monte, 2001; Torres, 1998; Camino, Silva \& Machado, 2003; Tougas, Brown, Beaton \& Joly, 1995).

Essas formas discriminatórias têm sido atualmente defendidas como sexismo, compreendida como um conjunto de estereótipos sobre a avaliação cognitiva, afetiva e atitudinal acerca do papel apropriado na sociedade dirigida aos indivíduos de acordo com o sexo (Expósito, Moya \& Glick, 1996; Glick \& Fiske, 1996; Myers, 1999). Consideradas como ambivalentes, justamente por não serem diretas quando se considera a prática e expressão discriminatória tradicional - enfatizando inferioridade ou diferença das mulheres como um grupo minoritário e merecedor da condição social em que estão vivendo - são encontradas em duas formas principais de sua manifestação: a hostil e a benévolo.

A primeira é uma expressão mais flagrante de preconceito em relação às mulheres, aproximando-se da definição clássica deste atributo psicossocial (Allport, 1954). Este tem sido extensamente tratado por Glick e Fiske (1996), porém não permite compreender totalmente a direção que toma o sexismo na sociedade atual, justificando a luz da busca de igualdade em direitos e deveres entre os gêneros, evidenciando crenças e práticas típicas de pessoas que consideram as mulheres inferiores aos homens, bem como, segundo Siano (2000), refletindo antipatia e intolerância em relação ao seu papel como figura de poder e decisão. A segunda se constitui a partir das concessões e tratamentos diferenciados entre homens e mulheres, referindo-se a uma atitude positiva, aparentemente não preconceituosa em relação à mulher, porém descrevendo-a como pessoa frágil, necessitando de atenção, etc.

Partindo dessa organização fatorial das dimensões do sexismo, pressupõem que este não ocorre no vazio social e que, mesmo a sua nova forma, só existe porque as pessoas passam a orientar suas condutas nas relações interpessoais a partir de uma base valorativa (Formiga, 2004). Isto é, ao tomarmos uma decisão, só a realizamos por- 
que somos capazes de priorizar e hierarquizar alguns valores na nossa interdependência social os quais orientam nossas escolhas, atitudes, avaliam os comportamentos e situações sociais, desta forma, a fazemos a partir da importância relativa que cada um de nós damos a um conjunto de valores para poder assim agir (Rokeach, 1973; Rokeach, 1979; Schwartz \& Bilsky, 1987; Gouveia, 1998).

Assim sendo, é baseado nos valores que diferenciamos os eventos entre o que é importante e secundário para nós, revelando tanto a relação com o comportamento e as opções na nossa vida quanto a preferência no que diz respeito ao que tem ou não valor no sentido axiológico (Tamayo, 1988). Tal conduta valorativa é capaz de expressar um forte componente a respeito do que queremos para nós mesmos, geralmente, evitando decepcionar-se consigo ou com as outras pessoas. Essa condição _ a prioridade dos valores entre as pessoas _ salieñta uma crença duradoura, isto é, uma maneira de se comportar ou um estado final de existência dela, os quais podem ser preferidos, tanto no âmbito pessoal quanto social (Gusmão, Jesus, Gouveia, Nunes Júnior \& Queiroga, 2001).

Tomando como base teórica a de que os valores podem orientar comportamentos e atitudes humanas frente aos fenômenos sociais, especificamente, o preconceito feminino, bem como partindo da definição que os valores humanos podem ser entendidos como categorias de orientação que são desejáveis, ba seadas nas necessidades humanas e nas pré-condições para satisfazêlas, sendo adotadas por atores sociais. Tais valores apresentam diferentes magnitudes e seus elementos constitutivos podem variar a partir do contexto social ou cultural em que a pessoa está inserida (Gouveia, 1998; p. 293). Este modelo apresenta 24 valores, distribuídos em seis funções psicossociais: existência, experimentação, realização, normativo, interacional e suprapessoal, reunindo-se em três critérios de orientação valorativa: pessoal, social e central.

Desta forma, considerando tais concepções sobre os valores, Formiga, Gouveia e Santos (2002) realizaram um estudo no qual avaliaram a relação entre essas variáveis, os valores humanos e sexismo ambivalente. Segundo esses autores, um conjunto de valores que formam o critério de orientação valorativa pessoal (a qual diz respeito às relações pessoais contratuais, visando obter vantagens/lucros, tendo seus próprios interesses como mais importantes) explicou tanto sexismo hostil quanto o benévolo; já o critério social (refere-se às pessoas que estão direcionadas a estarem com os outros, focalizando os interesses coletivos, respeito as tradições e normas sociais) correlacionou-se apenas com o benévolo. Via de resumo, os valores que visam um individualismo foram capazes de explicar ambas as formas do preconceito, já os que apontam para uma orientação social, salientou uma relação apenas com a discriminação sutil. Com isso, parece existir uma base normativa na organização dessas atitudes discriminatórias seja de uma forma direta visando a investida em valores de referência mais pessoal e individual ou na forma do estabelecimento das normas sociais e relações grupais, na qual é possível pensar que a orientação desses valores seja capaz, na dinâmica intergrupal, de estabelecer um preconceito sutil e discreto.

\section{MÉTODO}

\section{Amostra}

No presente estudo, duas amostras compostas entre estudantes universitários e transeuntes da população geral das cidades de Palmas TO e João Pessoa - PB foram utilizadas: uma continha 668 sujeitos (N1) e outra 795 sujeitos (N2). Em todas elas os sujeitos eram de ambos os gêneros, com idade que variava de 20 a 60 anos; nas três amostras observou-se a predominância de mulheres (68\%) e que $76 \%$ dos sujeitos eram casados. Esta amostra é não probabilística, podendo ser definida como intencional, pois eram consideradas as pessoas que, consultadas, dispuseram-se a colaborar, respondendo ao questionário que era apresentado, tanto nas instituições quanto nas ruas.

\section{Instrumentos}

Os participantes responderam aos seguintes questionários:

Inventário de Sexismo Ambivalente - ISA. Elaborado originalmente em língua inglesa por Glick e Fiske (1996), o instrumento é composto por 22 itens que avaliam os estereótipos assumidos pelo gênero a respeito de duas dimensões do sexismo: hostil (por exemplo, as mulheres feministas estão fazendo exigências completamente sem 
sentido aos homens; a maioria das mulheres não aprecia completamente tudo o que os homens fazem por elas) e benévolo (por exemplo, as mulheres devem ser quenidas e protegidas pelos homens; muitas mulheres se caracterizam por uma pureza que poucos homens possuem). Para respondê-lo, a pessoa deveria ler cada item e indicar o quanto está de acordo com o conteúdo expresso, para isso, numa escala de quatro pontos, tipo Likert, com os seguintes extremos $\mathbf{1}=$ Discordo Totalmente e $\mathbf{4}=$ Concordo Totalmente ele deveria indicar a resposta. Esta versão foi traduzida ao português por um psicólogo bilíngüe e avaliada por um outro da mesma categoria que a comparou com uma versão espanhola (Expósito, Moya \& Glick, 1998). Assim feito, procedeu-se a validação semântica do ISA; para tanto foi considerada uma amostra de 20 sujeitos da população meta. Esta assegurou que tanto os itens como as instruções do instrumento eram compreensíveis, passando a aplicar então a versão final. A partir de uma análise fatorial confirmatória, 0 inventário apresentou parâmetros psicométricos aceitáveis para a população brasileira com os seguintes indicadores de bondade de ajuste: $\underline{\mathrm{GFI}}=0,77 \mathrm{e} \underline{\mathrm{AGFI}}$ $=0,72 ; \mathrm{C} \_/ g . l .=3,18$; $\underline{\mathrm{RMSR}}=0,10$. (Formiga, Gouveia \& Santos, 2002).

Questionário dos Valores Básicos - QVB. Uma versão inicial foi proposta em espanhol e português, compreendendo então 66 itens, três para cada um dos valores básicos que avaliava (Gouveia, 1998). Utilizou-se uma versão modificada, cuja comprovação, a partir de uma análise fatorial confirmatória, apresentou parâmetros psicométricos aceitáveis na população estudada, tendo os seguintes indicadores de bondade de ajuste: $\mathrm{c}^{2} / \mathrm{gl}=3,02$, $\mathrm{GFI}=0,91, \mathrm{AGFI}=0,89$ e $\mathrm{RMSR}=0,07$ (Maia, 2000). Formado por 24 itens-valores, com etiquetas que ajudam a entender o seu conteúdo (por exemplo, Tradição - seguir as normas sociais do seu país; respeitar as tradições da sua sociedade; Exito - obter o que se propõe; ser eficiente em tudo que faz; Justiça Social - lutar por menor diferença entre pobres e ricos; permitir que cada indivíduo seja tratado como alguém valioso); para respondê-los, a pessoa deveria avaliar o seu grau de importância como um princípio-guia na sua vida e indicar sua resposta numa escala de sete pontos, com extremos $\mathbf{1}=$ Nada Importante a $\mathbf{7}=$ Muito Importante. No final precisava indicar o valor menos e o mais importante de todos, os quais receberiam pontuações $\mathbf{0}$ e $\mathbf{8}$, respectivamente.
Caracterização Sociodemográfica Uma folha separada foi anexada ao instrumento prévio, onde eram solicitadas informações de caráter sociodemográfico (por exemplo, idade, sexo, estado civil, etc.).

\section{Procedimento}

Procurou-se definir os seguintes procedimentos quanto à aplicação tanto do ISA (Inventário de Sexismo Ambivalente) quanto QVB (Questionário de Valores Básicos): 1 - nas instituições de ensino, estes instrumentos eram aplicados coletivamente em sala de aula quando em visita às instituições públicas e privadas. Nesta etapa, um único pesquisador ficou responsável pela coleta dos dados e após conseguir a autorização da coordenação dos cursos e professor responsável pela disciplina, este se apresentava em sala de aula como interessado em conhecer as opiniões e os comportamentos das pessoas no dia-a-dia, solicitando a colaboração voluntária dos estudantes no sentido de responderem a um questionário breve. 2 Em outra etapa, no que diz respeito à aplicação nas ruas das cidades, a aplicação era conduzida após conseguir a permissão dos transeuntes quando abordados, o aplicador se apresentava, também, como interessado em conhecer as opiniões e os comportamentos das pessoas no dia-a-dia, solicitando a colaboração voluntária deles no sentido de responderem a um questionário apresentado.

Nas duas etapas, foi-lhes dito que não havia respostas certas ou erradas e que respondessem individualmente; a todos era assegurado o anonimato da sua resposta e que seria tratada em seu conjunto, não podendo identificar, especificamente, o respondente isoladamente. Apesar de o questionário ser auto-aplicável, contando com as instruções necessárias para que possa ser respondido, um pesquisador devidamente treinado esteve presente durante toda a aplicação para retirar eventuais dúvidas ou realizar esclarecimentos que se fizessem indispensáveis. Um tempo médio de 15 minutos foi suficiente para concluir essa atividade.

\section{Tabulaçã o e Análise dos Dados}

O pacote estatístico SPSSWIN, em sua versão 11.0, foi utilizado para tabular os dados e realizar as análises estatísticas descritivas, bem como 
os cálculos referentes ao coeficiente de correlação $\underline{r}$ de Pearson.

\section{Resultados e discussão}

Considerando os resultados encontrados no estudo de Formiga, Gouveia e Santos (2002) quanto à interdependência entre o sexismo hostil e benévolo, pretendeu-se avaliar a partir de uma correlação de Pearson (ํ) se esses resultados ainda permanecem; sendo assim, observou-se uma relação direta e significativa, entre o sexismo benévolo e hostil nas duas amostras (N1 $[r=0,22]$ e N2 [ $r=0,24])$, mantendo o resultado semelhante ao estudo anterior. Considerado essa etapa, procurou-se atender o objetivo principal do presente estudo, o qual corresponde à avaliação da consistência correlacional entre valores humanos e sexismo ambivalente.

A partir de uma correlação de Pearson foram observados os seguintes resultados, tanto para a amostra N1 quanto a N2; todos eles podem ser observados na tabela 1: na amostra N1, é possível observar uma correlação positiva entre o Sexismo Hostil e as funções psicossociais dos valores de experimentação $(\underline{r}=0,15 ; \underline{p}<0,01)$ e realização $(\underline{r}=0,16 ; \underline{p}<0,01)$; em relação ao Sexismo Benévolo, a função valorativa normativa ( $\underline{r}=0,15$; $\underline{\mathrm{p}}<0,01)$, interacional $(\underline{\mathrm{r}}=0,17 ; \underline{\mathrm{p}}<0,01)$, realização $(\underline{r}=0,18 ; \underline{p}<0,01)$ e existência $(\underline{r}=0,10 ; \underline{p}<$ 0,01 ) estiveram também relacionadas positivamente. Para a amostra N2, efetuou-se semelhante procedimento estatístico, tendo os seguintes resultados: a função de experimentação $(\underline{r}=0,14 ; \underline{p}<$ $0,01)$ e realização $(\underline{r}=0,19 ; \underline{p}<0,01)$ apresentaram escores correlacionais positivos com o sexismo hostil; no que diz respeito ao sexismo benévolo, a função valorativa normativa ( $\underline{r}=0,21 ; \underline{p}<0,01)$, interacional $(\underline{r}=0,19 ; \underline{p}<0,01)$, realização $(\underline{r}=$ $0,19 ; \underline{p}<0,01)$ e existência $(\underline{r}=0,11 ; \underline{p}<0,01)$ apresentaram correlações positivas e significativas. Em ambas as amostras as correlações encontradas se diferenciaram apenas em pequenas variações em termos dos índices correlacionais, mas todas elas foram significativas.

\section{Tabela 1. Correlações entre as funções psicossociais dos valores e sex ismo a mbivalente.}

\begin{tabular}{|c|c|c|c|c|}
\hline \multirow{3}{*}{$\begin{array}{l}\text { FUNÇÕES PSICOSSOCIAIS } \\
\text { DOS VALORES HUMANOS }\end{array}$} & \multicolumn{4}{|c|}{ SEXISMO } \\
\hline & \multicolumn{2}{|c|}{ Hostil } & \multicolumn{2}{|c|}{ Benévolo } \\
\hline & N1 & $\mathbf{N 2}$ & N1 & $\mathbf{N 2}$ \\
\hline Experimentação & $0,15^{*}$ & $0,14^{*}$ & 0,03 & 0,05 \\
\hline Realização & $0,16^{*}$ & $0,19 *$ & $0,18 *$ & $0,19 *$ \\
\hline Existência & 0,04 & 0,06 & $0,10^{*}$ & $0,11 *$ \\
\hline Suprapessoais & 0,07 & 0,08 & 0,03 & 0,02 \\
\hline Interacionais & 0,06 & 0,04 & $0,17^{*}$ & $0,19 *$ \\
\hline Normativa & 0,05 & 0,03 & $0,15^{*}$ & $0,21 *$ \\
\hline
\end{tabular}

Notas: ${ }^{*} \mathrm{p}<0,01$ (teste unilateral; eliminação pairwise de casos em branco). N1 = 668, N2 = 795 .

Essas correlações podem ser acompanhadas como base para sua comprovação na figura 1; a título de síntese, pode ser visualizada uma curva sinusoidal que expressa a relação das funções psicossociais dos valores humanos com a pontuação total do sexismo ambivalente, podendo, com isso, apresentar um padrão correlacional entre as variáveis em ambas as amostras. Em toda a configuração da curva é possível observar uma variabilidade entre os valores e o sexismo; os valores que se encontram no pico e extremidades da curva representam uma influência positiva e significativa, abai- 
xo dela encontram-se os não significativos. Portanto, a adesão a esses valores implica, respectivamente, em endossar as atitudes discriminatórias frente às mulheres. Em ambas as amostras as funções psicossociais apontam em direção dessa prática discriminatória e sua semitria frente a uma base normativa do sexismo; simétrico, porque corresponde à semelhante relação ao estudo anterior, tendo apenas um cuidado quanto às diferenças entres os escores correlacionais, os quais variam devido à pontuação nas escalas de respostas dos sujeitos.

\section{Figura 1: Correlações entre as funções psicossociais dos valores e sexismo a mbivalente.}

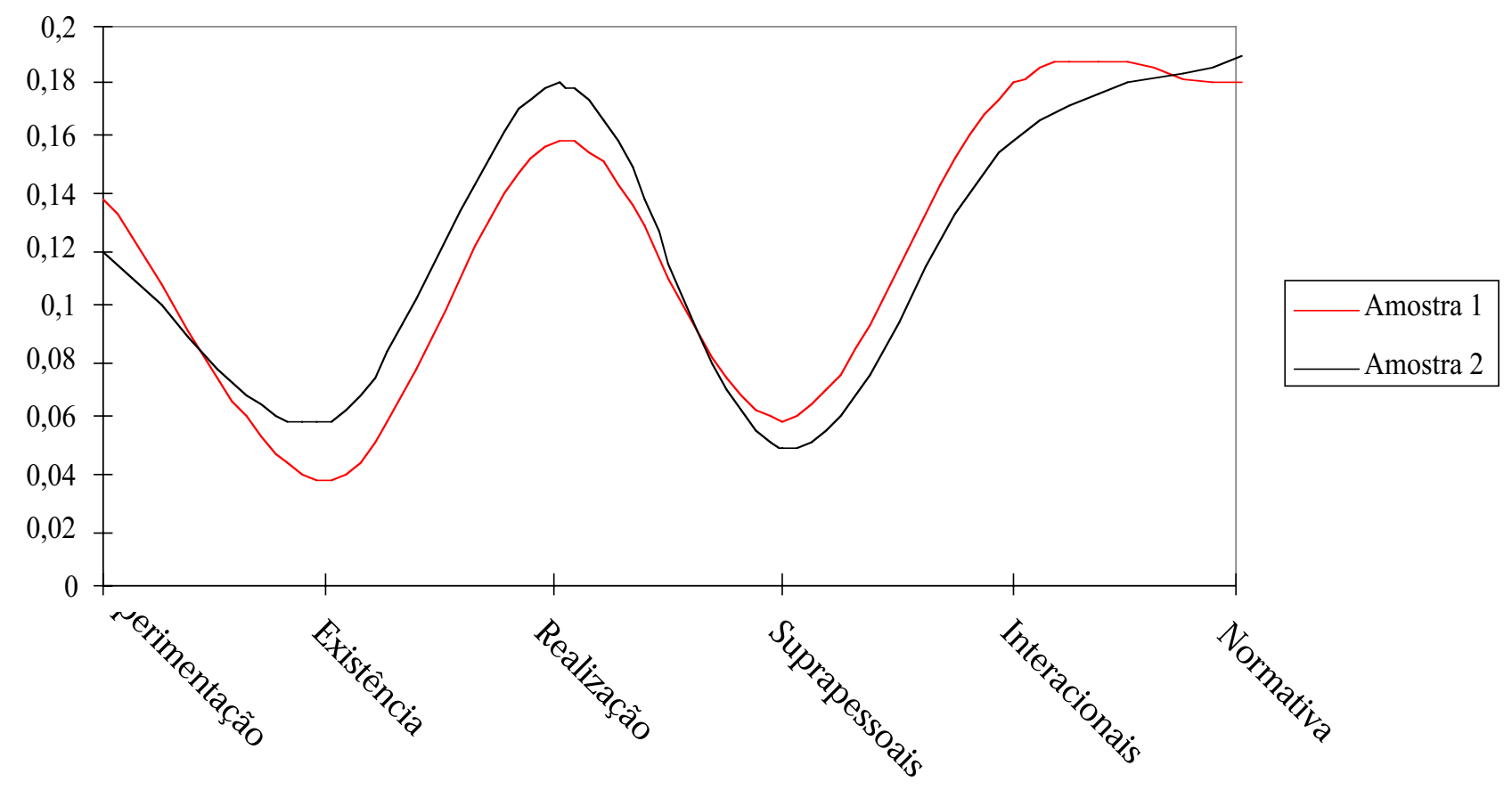

Considerando o modelo teórico dos valores humanos, estas funções psicossociais originam três critérios de orientação valorativa pessoal, social e central (ver Gouveia, 1998). Sendo assim, a partir de uma correlação de Pearson, procurou avaliar a relação entre essas orientações e o sexismo, encontrando os seguintes resultados: na amostra N1, o sexismo benévolo relacionou-se com 0 critério pessoal $(\underline{r}=0,11 ; \underline{p}<0,01)$ e social $(\underline{r}=$ 0,19; $\underline{p}<0,01)$; já o sexismo hostil correlacionou apenas com o critério pessoal ( $\underline{r}=0,13 ; \underline{p}<0,01)$. Em relação à amostra N2, o sexismo benévolo apresentou escores correlacionais com o critério social $(\underline{r}=0,24 ; \underline{p}<0,01)$ e pessoal $(\underline{r}=0,13 ; \underline{p}<$ $0,01)$; quanto ao sexismo hostil, observou-se uma correlação significativa apenas com o critério pessoal $(\underline{r}=0,20 ; \underline{p}<0,01)$. Nas duas amostras as correlações foram semelhantes entre os critérios de orientação valorativa e sexismo ambivalente (ver tabela 2). 
Tabela 2. Correlações entre os critérios da orientação valora tiva e sex ismo a mbivalente.

\begin{tabular}{|c|c|c|c|c|}
\hline \multirow{3}{*}{$\begin{array}{l}\text { CRITÉRIOS DE } \\
\text { ORIENTAÇÃO VALORATIVA }\end{array}$} & \multicolumn{4}{|c|}{ SEXISMO } \\
\hline & \multicolumn{2}{|c|}{ Hostil } & \multicolumn{2}{|c|}{ Benévolo } \\
\hline & N1 & N2 & N1 & N2 \\
\hline Pessoal & $0,13^{*}$ & $0,20^{*}$ & $0,11 *$ & $0,13^{*}$ \\
\hline Social & 0,01 & 0,01 & $0,19 *$ & $0,24^{*}$ \\
\hline Central & 0,01 & 0,02 & 0,04 & 0,06 \\
\hline
\end{tabular}

Notas: $* \mathrm{p}<0,01$ (teste unilateral; eliminação pairwise de casos em branco). N1 = 668; N2 = 795 .

A fim de um maior esclarecimento entre essas variáveis na tabela 2, optou-se pela elaboração de uma segunda figura que pudesse representar esses resultados encontrados. Nele é possível observar uma configuração tanto entre os critérios de orientação valorativa e o sexismo hostil e benévolo, quanto as correlações internas dos mesmos construtos. Com isso, não só podemos contemplar a relação direta entre os critérios valorativos pessoal e social com os tipos de sexismo, bem como a relação interna de cada um deles, vislumbrando um possível modelo relacional que contribua na compreensão do fenômeno do presente estudo (ver figura 2).

\section{Figura 2: Representa ção das correlações entre os critérios de orienta ção valo- rativa e os tipos de sex tismo nas duas amostras (N1 e N2).}

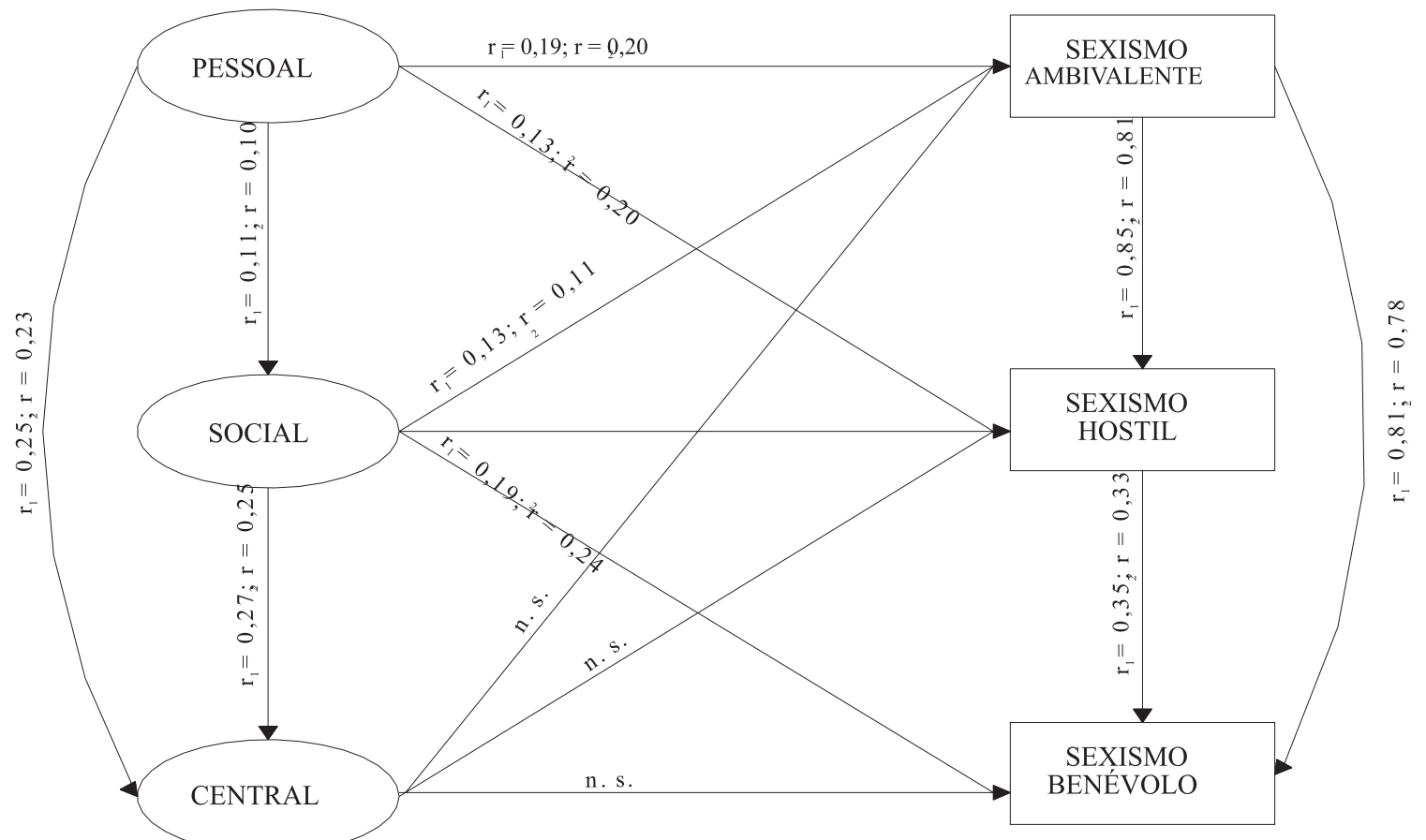

Nota: Com excecão do critério valorativo central todas as outras correlações foram significativa a um $\mathrm{p}<0,01$ 
Como dado adicional, resolveu-se avaliar a diferença ente as médias da pontuação de homens e mulheres nas variações do sexismo em ambas as amostras. Sendo assim, a partir de um teste $t$ de student é possível visualizar essas diferenças; especificamente, no que se refere ao Sexismo Bénevolo na amostra N1 [t(601) =3,42, $\underline{\mathrm{p}}<$ $0,01]$ as mulheres apresentaram uma média superior $\left(\mathrm{M}_{\mathrm{N} 1}=3,40, \mathrm{DP}_{\mathrm{N} 1}=0,66\right)$ à dos homens $\left(\mathrm{M}_{\mathrm{N} 1}=\right.$ $\left.2,48, \mathrm{DP}_{\mathrm{N} 1}=0,72\right)$; o mesmo ocorreu na N2 [t(760) $=2,65, \underline{p}<0,05]$, observando uma média para as mulheres $\left(\mathrm{M}_{\mathrm{N} 2}=3,41, \mathrm{DP}_{\mathrm{N} 2}=0,70\right)$ maior do que a dos homens $\left(\mathrm{M}_{\mathrm{N} 2}=3,01, \mathrm{DP}_{\mathrm{N} 2}=0,68\right)$. Esta situação se inverteu no caso do Sexismo Hostil, no qual os homens, na amostra N1 [t(602) $=6,87, \underline{p}<0,01]$, pontuaram mais alto $\left(\mathrm{M}_{\mathrm{N} 1}=3,29, \mathrm{DP}_{\mathrm{N} 1}=0,69\right)$ do que as mulheres $\left(\mathrm{M}_{\mathrm{N} 1}=2,87, \mathrm{DP}_{\mathrm{N} 1}=0,72\right)$. Na amostra N2 $[\mathrm{t}(763)=8,21, \underline{\mathrm{p}}<0,01]$ os resultados foram bem semelhantes, onde os homens apresentaram médias maiores $\left(\mathrm{M}_{\mathrm{N} 2}=3,30, \mathrm{DP}_{\mathrm{N} 2}=0,70\right)$ do que das mulheres $\left(\mathrm{M}_{\mathrm{N} 2}=2,85, \mathrm{DP}_{\mathrm{N} 2}=0,70\right)$.

\section{Tabela 3: Dimensões do Sex ismo Ambivalente entre Homens e Mulheres}

\begin{tabular}{|c|c|c|c|c|c|c|c|c|}
\hline & & \multicolumn{4}{|c|}{ Gênero } & & & \\
\hline & & HON & EM & MUL & ER & & Estat & cas \\
\hline \multirow[t]{2}{*}{ Sexismo Ambivalente } & & M & DP & M & DP & $\underline{\mathrm{t}}$ & gl & $\underline{p}<$ \\
\hline & N1 & 2,48 & 0,72 & 3,40 & 0,66 & 3,42 & 601 & 0,05 \\
\hline \multicolumn{9}{|l|}{ Benévolo } \\
\hline & $\mathrm{N} 2$ & 3,01 & 0,68 & 3,41 & 0,70 & 2,65 & 760 & 0,05 \\
\hline & N1 & 3,29 & 0,69 & 2,87 & 0,72 & 6,87 & 602 & 0,01 \\
\hline \multicolumn{9}{|l|}{ Hostil } \\
\hline & $\mathrm{N} 2$ & 3,30 & 0,70 & 2,85 & 0,70 & 8,21 & 763 & 0,01 \\
\hline
\end{tabular}

Notas: $\mathrm{N} 1=668 ; \mathrm{N} 2=795$.

Ao considerar os resultados desse estudo, é preciso destacar os seguintes pontos: 1 - nessas duas amostras, foi observada sua corroboração com um estudo pioneiro desenvolvido por Formiga, Gouveia e Santos (2002; ver também, Gouveia, Silva \& Belo, 2003), revelando semelhante direção com os resultados encontrados no atual trabalho, tanto para as funções psicossociais quanto aos critérios de orientação valorativa. Assim, o sujeito que apresente uma adesão a um conjunto de valores que origine a função de experimentação _ enfatizando a descoberta e apreciação de estímulos novos, enfrentamento de situações arriscadas, etc. - possivelmente, poderá ser capaz de manifestar o sexismo hostil; vale destacar que a função valorativa de realização _ visando o auto cumprimento, sentimento de ser importante e poderoso, ser uma pessoa com identidade e espaço próprios - não somente poderá influenciar o sujeito ao sexismo tradicional ou hostil, mas também, ao benévolo, aquele preconceito mais sutil ou camuflado.

Uma função valorativa que merece ser considerada e que não apresentou resultado significativo no estudo de Formiga e colaboradores (2002) diz respeito à função valorativa de existência - a qual faz referência às pessoas que interessa garantir a própria existência orgânica, os quais são importantes, principalmente em ambientes de escassez econômica, porém, não coloca em risco a harmonia social - que relacionou com o sexismo benévolo; tal fato pode contribuir em direção da reflexão quanto a insegurança econômica e o aparecimento do preconceito, bem como, a influência dessas condições no acesso de traços de personalidade no eixo temperamental de rigidez mental e 
desejabilidade social (ver Amadio, Omar \& Formiga, 2002).

A surpresa da relação entre essas variáveis deve-se por encontrar em outros estudos a existência de correlações baixas ou nenhuma; assim, se tomarmos essa função como representação especular das relações intergrupais entre homens e mulheres, podemos observar justamente os processos de inibição quanto à competição e ascensão do poder da mulher às categorias sociais e profissionais, pois parece salientar perigo de escassez socioeconômica aos homens. Com isso, é possível compreender a orientação masculina na distribuição de atividades e atribuição de traços personalísticos na o cupação delas, atingindo, assim, a vida individual deles (Amâncio, 1994). Ao refletir sobre esse resultado, é possível entender, mas não aceitar, o discurso masculino em relação à mulher em não se comprometer com atividades fora de casa, porque os filhos ou a casa precisam de atenção, etc. $O$ que essa orientação vem transparecer mesmo é a camuflagem discriminatória em relação à mulher, tentando se mostrar como cuidadoso, respeitoso ou preocupado com ela, mas o que vê revelar de fato são as novas formas de preconceito.

Um outro resultado que revela com uma maior clareza esse fenômeno pode ser observado na relação entre as funções normativas e interacionais, ambas buscam a estabilidade do grupo e o respeito para com os símbolos e padrões culturais, bem como os que focalizam o destino comum e a complacência, o interesse em ser amada e ter uma amizade verdadeira, assim como, tende a apreciar uma vida social ativa. Sendo assim, esse tipo de sexismo, ao ser explicado por tais funções valorativas, pode ser compreendido quando a pessoa adere a esses valores, produz um discurso de conformismo em relação à vida e sua dinâmica social, tendo como algo inalterável. Com isso, o novo sexismo surge na sociedade discretamente nas relações intergrupais, salientando a sua não existência e tendo uma característica de conformidade positiva, isto é, pode-se a ele assumir um discurso de que "não estar me incomodando, não vejo problema nisso". Tanto se discrimina a partir de uma atitude positiva, aparentemente, não preconceituosa em relação à mulher quanto pela expressão direta do pre- conceito feminino (Formiga, Yepes \& Alves, 2004).

Essas funções psicossociais, destacadas na tabela 1 , formam os critérios de orientação valorativa; estes dizem respeito ao sujeito que nas suas relação sociais se orientam a partir de condutas individualistas ou coletivistas. Na tabela 2 foi possível observar que o critério pessoal, composto pelas funções de experimentação e realização, salienta o sujeito que se orienta por um conjunto de valores capazes de manter as relações pessoais contratuais, procurando obter vantagens/lucros bem como priorizar seus próprios interesses e sua intrapessoalidade, tendo probabilidade de apresentar ambos os tipos de sexismo (Rokeach, 1973; Schwartz, 1994). Isto não apenas é uma referência individual, mas também estabilizada na social. Por outro lado, ao aderir uma orientação social, a qual diz respeito às pessoas direcionadas para estarem com os outros, focalizando a interpessoalidade e o interesse coletivo, é capaz de contribuir para a manutenção de atitudes discretas e sutis do sexismo e suas variações, afinal, o preconceito frente às mulheres, por estar hoje tão deflagrado, não pode mais ser direto, tratando-o muitas vezes recheadas de "humor" (achincalho, piadas, brincadeiras etc.) áspero, porém, visto nas relações como nada ofensivo (Rokeach, 1973; Schwartz, 1994; Thomas \& Esses, 2004).

No que diz respeito à diferença de gênero e sexismo, os resultados revelaram a capacidade de que a aceitação de um ou outro tipo desse construto pode ter como referência o espaço psicossocial que tanto as mulheres quanto os homens permitem a sua manifestação, comprovando, assim, o preconceito instrumental e direto ou o sutil. Desta forma, é possível refletir na seguinte direção: a nova forma desse fenômeno só ocorre porque é sustentado pelas crenças femininas, de que a benevolência e consciência de estar sendo bem tratada e uma dedicação atenciosa não têm nada a ver com o processo discriminatório. De fato, a discriminação parece atender aos objetivos implícitos da sociedade, principalmente, quando há uma mudança e êxito da mulher em qualquer esfera social; esse fato visa atender as expectativas propostas pela sociedade de uma luta e expressividade quanto a não discriminação, 
as quais são capazes de filtrar condições mais diretas, relacionando um processo mais depurado do preconceito e gerando a construção de normas sociais concordantes na interação social (Camino, Silva \& Machado, 2003; Fiúza, 2001).

Esses resultados deflagram o quanto a sociedade está impregnada de ideologias que guiam e justificam as condutas do indivíduo, fazendo-as "comuns" e embasadas em práticas que geralmente são adotadas por esquemas psicológicos e ideológicos que refletem comportamentos a respeito da formação discriminatória de papéis sexuais socialmente aceitos, justificando-os como valores de uma sociedade ou grupo "impossível" de alterá-la, fazendo a pessoa se conformar; porém, não impede a condição da autoconfrontação desses valores e suas influências atitudinais e comportamentais, fazendo com que as pessoas girem sociocognitivamente o que de fato as formas educativas e cavalheirescas frente às mulheres escondem de verdade (Paéz, Torres \& Echebarría, 1990). A aparição do sexismo, tanto benévolo quanto hostil, é sem dúvida um problema no âmbito da pretendida relação de igualdade e de justiça social, bem como de sua manifestação evidente de específicas orientações valorativas das pessoas; assim, tal fato revela não uma diminuição ou rejeição desse fenômeno, mas que sua manifestação flutua numa base normativa do preconceito (Formiga, Gouveia \& Santos, 2001).

Por fim, além de ter a influência entre valores e sexismo comprovada, tendo observado a estabilidade entre as relações dessas variáveis, esses resultados poderiam vislumbrar uma contribuição em programas para a intervenção nos valores humanos para a redução do preconceito entre as pessoas, salientado que este construto é capaz de orientar as condutas das pessoas em relação aos mais diversos grupos, principalmente os minoritários; assim, seria possível identificar um caminho para amenizar atitudes preconceituosas, consecutivamente, fenômenos mais graves, por exemplo, a violência feminina. Espera-se que os objetivos do estudo tenham sido cumpridos; observou-se que tanto os valores que apontam para uma orientação pessoal quanto social podem explicar o sexismo, pois não somente o sujeito que visa os próprios interesses, mas também o que se preocupa com as tradições, contribui para a manutenção desse fenômeno.

\section{Referências}

Allport, G. W. (1954). The nature prejudice. Reading, MA: Adison-Wesley Publishing Company.

Amadio, O. D., Omar, A., \& Formiga, N. S. (2002). La emergencia del prejuicio discriminatorio: A la luz de la inseguridad socioeconomica percibida (pp. 32). In: Anais, 1 Congresso Brasileiro Psicologia: Ciência \& Profissão. 2002, São Paulo: SIP.

Amâncio, L. (1994). Masculino e feminino. A construção social da diferença. Porto: Afrontamento.

Camino, L., Silva, P., \& Machado, A. O. (2003). Novas formas de preconceito racial: racismo sutil ou mascarado (pp. 236). In: 3 Congresso Norte-Nordeste de Psicologia. Construindo A Psicologia Brasileira: Desafios da Ciência e Prática Psicológica. 2003, João Pessoa: PB.

Expósito, F., Moya, M. C., \& Glick, P. (1998). Sexismo ambivalente: Medición y correlatos. Revista de Psicologia Social, 13, 159-169.

Fiúza, A. L C. (2001). Mulheres nas políticas de desenvolvimento sustentável. In: C. Bruschini, \& C. R. Pinto (Org.). Tempos e lugares de gênero. (pp. 87-118). São Paulo: Editora 34.

Formiga, N. S. (2004). As bases normativas do sexismo ambivalente: A sutileza do preconceito frente as mulheres à luz dos valores humanos básicos. In: M. Lima, E. O. Perreira, \& E, Marcos. (Orgs.). Estereótipos, preconceitos e discriminação: Perspectivas teóricas e metodológicas. (pp. 259-276.). Salvador: UFBA.

Formiga, N. S., Gouveia, V. V., \& Santos, M. N. (2002). Inventário de sexismo ambivalente: sua adaptação e relação com o gênero. Revista Psicologia em Estudo, 7(1), 105-111.

Formiga, N. S., Yepes, C. F., Alves, I., Ayroza, I., Teixeira, J., \& Curado, F. (2004). Flagrando o preconceito: Uma análise descritiva das atitudes preconceituosas frente aos negros, mulheres e homossexuais. In: Anais, 34 Reunião Anual Da Sociedade Brasileira De Psicologia. Formação Do Psicólogo Brasileiro: História De Desafios E Conquistas. Ribeirão Preto, SP: 26 a 29 de Outubro. [Resumo eletrônico]. 
Glick, P., \& Fiske, S. T. (1996). The Ambivalent Sexism Inventoy: Differentiating hostile and benevolent sexism. Journal of Personality and Social Psychology, 70, 491-521.

Gouveia, V. V., Silva, R., \& Belo, R. P. (2003). Sexismo ambivalente e valores humanos (pp. 242243). In: 3 Congresso Norte-Nordeste de Psicologia. Construindo A Psicologia Brasileira: Desafios da Ciência E Prática Psicológica. 2003, João Pessoa, PB: 27 a 31 de maio. Volume 1.

Gouveia, V. V. (1998). La naturaleza de los valores descriptores del individualismo e del colectivismo: Una comparación intra e intercultural. Tese de Doutorado, Faculdade de Psicologia, Universidade Complutense de Madri, Espanha.

Gusmão, E. E. S., Jesus, G. R., Gouveia, V. V., Júnior, J. N., \& Queiroga, F. (2001). Interdependência social e orientações valorativas em adolescentes. Revista Psicologia, 32, 23-37.

Maia, L. M. V. (2000). Prioridades valorativas e desenvolvimento moral: Considerações acerca de uma teoria dos valores humanos. Dissertação de mestrado não publicada, Universidade federal da Paraíba, João Pessoa, PB.

Monte, D. F. C. (2001). Aspectos do preconceito étnico em relação ao negro: Um estudo empírico no setor supermercadista de João Pessoa, PB. Dissertação de mestrado, Universidade federal da Paraíba, João Pessoa, PB.

Myers, D. G. (1999). Preconceito: O ódio ao próximo. In: Psicologia Social (pp.181-206). Rio de Janeiro: LTC.

Páez, D., Torres, B., \& Echebarria, A. (1990). Esquema de si, representación social y estereotipo sexual. In: G. Musitu (Org.). Procesos psicosociales básicos (pp. 229-234). Barcelona: PPU.
Pettigrew, T. F., \& Meertens, R. W. (1995). Subtle and blatant prejudice in Western Europe. European journal of social psychology, 25, 57-75.

Rokeach, M. (1973). The nature of human values. New York: Free Press.

Rokeach, M. (1979). Introduction. In: M. Rokeach (Ed.), Understanding human values: Individual and societal (pp. 1-11). New York: The Free Press.

Schwartz, S. H. \& Bilsky, W. (1987). Toward an universal psychological structure of human values. Journal of Personality and Social Psychology, 53, 550-562.

Schwartz, S. H. (1994). Are there universal aspects in the structure and contents of human values? Journal of Social Issues, 50, 19-45.

Siano, J. A. (2000). Constituição da Republica Federativa do Brasil. São Paulo: Rideel.

Swin, J. K., Aikin, K. J., Hall, W., S. \& Hunter, B. A. (1995). Sexism and racism: Old-fashioned and modern prejudices. Journal of Personality and Social Psychology, 68, 199-214.

Tamayo, A. (1988). Influência do sexo e da idade sobre o sistema de valores. Arquivos Brasileiros de Psicologia, 40, 91-104.

Thomas, C. A., \& Esses, V. M. (2004). Individual differences in reactions to sexist humor. Group Processes \& Intergroup Relations, 7(1), 89-100.

Torres, R. R. (1998). La influencia de la inducción afectiva sobre el prejuicio racial. Revista de psicología social, 2(13), 279-289.

Tougas, F., Brown, R., Beaton, A. N., \& Joly, S. (1995). Neosexism: Plus ça change, Plus c'est pareil. Personality and social psychology behavior, 21(8), 842-849.

Recebido em/received in: 17/10/2005 Aprovado em/approved in: 12/09/2006 